\title{
Características físico-químicas e sensoriais de embutido fresco de aves de descarte preparado com diferentes antioxidantes naturais
}

\author{
Physical-chemical and sensory characteristics of spent hens meat sausage prepared with \\ different naturals antioxidants
}

\author{
BORBA, Hirasilva ${ }^{1 *}$; SCATOLINI-SILVA, Aline Mary ${ }^{1}$; GIAMPIETRO-GANECO, \\ Aline $^{1}$; BOIAGO, Marcel Manente ${ }^{2}$; SOUZA, Pedro Alves ${ }^{1}$
}

\author{
${ }^{1}$ Universidade Estadual Paulista, Faculdade de Ciências Agrárias e Veterinárias, Departamento de \\ Tecnologia, Jaboticabal, São Paulo, Brasil. \\ ${ }^{2}$ Universidade do Estado de Santa Catarina, Chapecó, Santa Catarina, Brasil. \\ *Endereço para correspondência: hiras@fcav.unesp.br.
}

\section{RESUMO}

Objetivou-se avaliar o efeito de diferentes antioxidantes naturais em embutidos frescos formulados com carnes provenientes de aves de descarte nas características físico-químicas e sensoriais do produto. $\mathrm{O}$ experimento foi realizado no Departamento de Tecnologia - Laboratório de Tecnologia dos Produtos de Origem Animal da FCAV/Unesp - Campus de Jaboticabal. Para tanto, foram utilizadas 45 aves de postura, com aproximadamente 80 semanas de idade, distribuídas em um delineamento inteiramente casualizado em esquema fatorial $4 \times 4$, sendo quatro tipos de condimentos (controle, alecrim, cravo-da-índia e orégano) e quatro períodos de armazenamento (zero, três; seis e nove dias a $4^{\circ} \mathrm{C}$ ), o que totalizou 16 tratamentos e três repetições. Foram ainda avaliadas as características de umidade, $\mathrm{pH}$, cor, perdas por cozimento, força de cisalhamento, número de TBARS e análise sensorial. As médias obtidas foram comparadas pelo teste de Tukey a 5\% de significância. Houve interação entre o período de armazenamento e o condimento utilizado em todas as características avaliadas. $\mathrm{O}$ tratamento que continha cravo da Índia foi o que recebeu as menores notas na análise sensorial. A utilização do orégano diminuiu a oxidação do embutido, além de ter agradado os provadores na análise sensorial.

Palavras-chave: armazenamento, carne de frango, qualidade

\section{SUMMARY}

The present study evaluated the effect of the use of natural antioxidants in different spent hens processed meat, the physical-chemical and sensory characteristics of product were analyzed. The experiment was conducted at the Technology Laboratory of Animal Products, Department of Technology - FCAV / Unesp - Campus of Jaboticabal. Forty-five laying hens with approximately 80 weeks of age were used, distributed in a completely randomized experimental design in a $4 \times 4$ factorial arrangement, 4 condiment types (control, rosemary, clove and oregano, and the last three natural antioxidants) and 4 storage times $\left(0 ; 3 ; 6\right.$ and 9 days at $\left.4^{\circ} \mathrm{C}\right)$, with sixteen treatments and tree repetitions. It were evaluated the characteristics of humidity, $\mathrm{pH}$, color, cooking loss, shear force, TBARS number and sensory analyze. The averages were obtained by Tukey test $5 \%$ of significance. The results showed an interaction between the storage time and condiments types in all analyzed parameters. It was concluded that oregano use decreased the processed meat oxidation, also pleased the judges in sensory analysis. The lowest notes in sensory analysis were obtained with the treatment that contained clove.

Keywords: poultry, quality, storage 


\section{INTRODUÇÃOO}

As aves de descartes sempre são abatidas com idade avançada. É comum que apresentem uma carne mais firme e menos suculenta. Essa característica dificulta a comercialização da carcaça, dos cortes e dos filés (SOUZA et al., 2006). O destino desses animais, muitas vezes é o abate e a incineração, prática que além de não gerar lucros, acarreta custos e causa problemas ambientais (GARCIA et al., 2002).

Komiyama et al. (2010), ao estudarem carne de peito de matrizes pesadas de descarte, observaram que a carne oriunda dessas aves apresenta características de qualidade tecnológica que possibilitam sua utilização como matéria-prima para a elaboração de industrializados.

Contudo, um dos desafios no processamento de carne, tanto branca, quanto escura, está na conservação dos produtos (ANTUNES et al., 2003). A oxidação lipídica, em razão da alta concentração de ácidos graxos polinsaturados, constitui um fator preocupante, principalmente em carne escura de frango, devido seu alto teor de ferro e fosfolipídios.

Os antioxidantes sintéticos são utilizados pelas indústrias de alimentos para prolongar a vida de prateleira de carnes e produtos cárneos. No entanto, devido à crescente preocupação com a saúde, observa-se uma demanda cada vez maior por parte dos consumidores por produtos de origem natural. Assim, o uso de condimentos como antioxidantes naturais tem sido objeto de estudo em pesquisas que empregam diversas matrizes cárneas como hambúrgueres, almôndegas, embutidos, desidratados e cortes marinados (MARIUTTI et al., 2008).

A utilização de antioxidantes naturais em produtos cárneos apresenta vantagem da aceitação imediata pelo consumidor e sua utilização não é limitada pela legislação. $\mathrm{O}$ alecrim, um condimento bastante conhecido, tem sido extensamente estudado em alimentos por sua atividade antioxidante. Nassu et al. (2002) avaliaram sensorialmente embutidos de carne caprina com diferentes níveis de inclusão de alecrim $(0,025$ e $0,05+\%)$ e observaram maior aceitação desses tratamentos em relação ao controle, o que confirma o efeito benéfico do uso de antioxidante na impressão global do produto.

Dessa forma, objetivou-se neste estudo avaliar características físico-químicas e sensoriais de embutidos preparados com carne de aves de postura de descarte que utilizava-se de diferentes antioxidantes naturais, em quatro períodos de armazenamento.

\section{MATERIAL E MÉTODOS}

A carne do peito e pernas provenientes de 45 aves de postura da linhagem Isa Brown, com aproximadamente 80 semanas de idade e com peso vivo médio de $1,8 \mathrm{~kg}$ foi utilizada neste experimento. As aves foram abatidas seguindo o fluxo de abate de frangos de corte em abatedouro comercial.

Após o abate, as carcaças foram enviadas refrigeradas $\left(6\right.$ a $\left.10^{\circ} \mathrm{C}\right)$ ao Departamento de Tecnologia - Laboratório de Tecnologia dos Produtos de Origem animal, onde foram separados os peitos e pernas, desossados manualmente $\mathrm{e}$ posteriormente moídos em discos de $8 \mathrm{~mm}$ (por duas vezes) para preparo da massa e confecção do embutido fresco de acordo com os tratamentos.

Os ingredientes utilizados na formulação dos embutidos frescos foram: sal (3,0\%), açúcar $(0,3 \%)$, alho $(0,4 \%)$, pimenta-doreino $(0,2 \%)$, pimenta-jamaica $(0,1 \%)$, noz-moscada $(0,1 \%)$, cebola $(2 \%)$, 
toucinho suíno (15\%), carne moída de peitos e pernas $(78,75 \%)$ e os diferentes oxidantes naturais testados (alecrim, cravo-da-índia e orégano) com inclusão de $0,15 \%$.

Após a incorporação manual dos ingredientes na carne, a massa foi colocada em bandejas individuais previamente identificadas quanto à adição dos antioxidantes e acondicionadas em geladeira $\left(4{ }^{\circ} \mathrm{C}\right)$ por 12 horas, para posterior embutimento em tripas suínas com $2 \mathrm{~cm}$ de diâmetro, previamente higienizadas (lavadas com água potável e deixadas de molho em solução de ácido acético a 10\%). Depois de prontas as amostras de linguiça (nove "gomos" de $10 \mathrm{~cm}$, para cada tratamento), foram embaladas em sacolas de polietileno (impermeáveis à umidade) e armazenadas em geladeira $\left(4^{\circ} \mathrm{C}\right)$ até serem analisadas.

Foi utilizado um delineamento inteiramente casualizado (DIC) em esquema fatorial $4 \quad \mathrm{x} \quad 4 \quad$ (quatro antioxidantes - controle, sem adição de antioxidante natural, alecrim, cravo-daíndia e orégano, e quatro períodos de armazenamento: zero, três, seis e nove dias a $4^{\circ} \mathrm{C}$ ), o que somou 16 tratamentos e três repetições.

Foram avaliadas estas características: umidade, $\mathrm{pH}$, cor, perdas por cozimento, força de cisalhamento, número de substâncias reativas ao ácido tiobarbitúrico (TBARs) e análise sensorial. A umidade foi determinada nas amostras cruas segundo o método descrito pela AOAC (2000) e os resultados expressos em porcentagem. $\mathrm{O} \mathrm{pH}$ foi determinado em peagâmetro digital, por meio de de um eletrodo introduzido diretamente no embutido fresco.

A análise de cor foi realizada na amostra crua a partir da utilização de colorímetro (Minolta Chromer Meter CR-300) e a escala CIELAB ( $\left.L^{*}, a^{*}, b^{*}\right)$, onde, L luminosidade, a - intensidade de vermelho e $b$ - intensidade de amarelo.
As perdas por cozimento foram determinadas de acordo com metodologia descrita por Corte et al. (1979) e os resultados expressos em porcentagem. Também foi realizada a determinação da força de cisalhamento, para a qual as amostras foram cortadas de forma padronizada e submetidas ao corte com utilização da lâmina Warner-Bratzler, acoplada ao aparelho Texture Analyser $T A-X T 2 i$, e os resultados expressos em $\mathrm{kgf} / \mathrm{cm}^{2}$. O número de substâncias reativas ao ácido tiobarbitúrico (TBARs) foi determinado nas amostras cruas do embutido, conforme a metodologia descrita por Pikul et al. (1989), e os resultados expressos em $\mathrm{mg}$ de TMP(tetrametoxipropano)/kg de amostra. Foram coletadas amostras (gomos) aleatórias dos tratamentos para análise sensorial, as quais foram assadas, em forno a gás tipo padaria (Tedesco FB 726), pré-aquecido a $170^{\circ} \mathrm{C}$, até a temperatura interna (aferida com termômetro digital da marca Multi-Thermometer) das amostras atingir $75^{\circ} \mathrm{C}$. Em seguida, as amostras foram uniformemente cortadas com altura de $2 \mathrm{~cm}$ e servidas quentes, em pratos previamente identificados com numeração aleatória codificadas em três dígitos. Em cabines individuais com luz fluorescente (do tipo "luz do dia"), localizadas no Laboratório de Tecnologia dos Produtos de Origem Animal, 30 provadores nãotreinados avaliaram as amostras para os atributos de sabor, textura e aceitação, por meio do uso da escala hedônica não estruturada de 9 pontos (MEILGAARD et al., 1991).

A preferência das amostras também foi avaliada. As amostras foram analisadas ao final de cada período de armazenamento (zero, três, seis e nove dias). Cada provador recebeu uma amostra de cada tratamento (sem adição de antioxidante natural, alecrim, cravoda-índia e orégano). 
Rev. Bras. Saúde Prod. Anim., Salvador, v.13, n.2, p.360-370 abr./jun., 2012 http://www.rbspa.ufba.br ISSN 15199940

Para cada característica estudada, os resultados dos tratamentos foram avaliados por análise de variância segundo procedimentos do sistema operacional SAS (1999) e as comparações das médias foram realizadas pelo teste de Tukey a 5\% de significância.

\section{RESULTADOS E DISCUSSÃO}

De acordo com os dados analisados (Tabela 1), pode-se observar que houve interação entre período de armazenamento e antioxidante em todas as características estudadas.

Tabela 1. Valores obtidos para $\mathrm{pH}$, TBARS, umidade, força de cisalhamento (FC) e perdas por cocção (PPC) nas amostras de embutidos frescos preparados com carne de poedeiras de descarte contendo diferentes antioxidantes naturais e armazenados por diferentes períodos

\begin{tabular}{|c|c|c|c|c|c|}
\hline Tratamentos & $\mathrm{pH}$ & $\begin{array}{c}\text { TBARS } \\
\text { (mg TMP/g) }\end{array}$ & $\begin{array}{c}\text { Umidade } \\
(\%)\end{array}$ & $\begin{array}{c}\mathrm{FC} \\
\left(\mathrm{kgf} / \mathrm{cm}^{2}\right)\end{array}$ & $\begin{array}{l}\text { PPC } \\
(\%)\end{array}$ \\
\hline & \multicolumn{5}{|c|}{ Condimentos $(\mathrm{C})$} \\
\hline Controle & 5,86 & 0,31 & 64,70 & 4,284 & 23,16 \\
\hline Cravo & 5,83 & 0,38 & 63,91 & 4,719 & 24,91 \\
\hline Orégano & 5,87 & 0,28 & 61,41 & 4,483 & 20,44 \\
\hline Alecrim & 5,87 & 0,35 & 63,72 & 4,151 & 25,23 \\
\hline DMS & 0,041 & 0,024 & 1,47 & 412,20 & 4,27 \\
\hline \multirow[t]{2}{*}{ Teste F } & $2,93 *$ & $55,32 * *$ & $13,46 * *$ & $5,30 *$ & $3,86^{*}$ \\
\hline & \multicolumn{5}{|c|}{ Armazenamento em dias (A) } \\
\hline 0 & 5,86 & 0,27 & 63,76 & 4,532 & 24,66 \\
\hline 3 & 5,95 & 0,35 & 64,24 & 4,186 & 29,16 \\
\hline 6 & 5,93 & 0,30 & 62,74 & 4,168 & 16,03 \\
\hline 9 & 5,68 & 0,40 & 63,01 & 4,752 & 23,89 \\
\hline DMS & 0,041 & 0,023 & 1,47 & 412,20 & 4,27 \\
\hline Teste F & $133,04 * *$ & $76,63 * *$ & $3,19 *$ & $6,93 *$ & $23,95 * *$ \\
\hline F p/ Int. CxA & $2,70^{*}$ & $22,29^{*}$ & $4,74 *$ & $2,70^{*}$ & $5,07 *$ \\
\hline $\mathrm{CV}(\%)$ & 0,63 & 6,44 & 2,10 & 8,45 & 16,48 \\
\hline
\end{tabular}

$\mathrm{Na}$ mesma coluna, médias seguidas de letras diferentes indicam diferença significativa pelo teste de Tukey a $5 \%$ de probabilidade. DMS = Diferença Mínima Significativa. * $(\mathrm{P}<0,05) ; * *(\mathrm{P}<0,01)$, $\mathrm{CV}=$ Coeficiente de variação.

Todos os condimentos avaliados, inclusive o grupo controle, apresentaram queda de $\mathrm{pH}$ no nono dia de armazenamento, já nos demais períodos o pH das amostras se manteve estável até ao sexto dia, sem diferir estatisticamente ( $>>0,05)$.

Também no nono dia de armazenamento foi verificada diferença estatística $(\mathrm{p}<0,05)$ para $\mathrm{pH}$, entre os tipos de condimento: a amostra que continha cravo apresentou $\mathrm{pH}$ menor que as demais $(p<0,05)$, o que indica que a utilização dessa especiaria pode ser muito útil na conservação de embutidos (Tabela 2). 
Rev. Bras. Saúde Prod. Anim., Salvador, v.13, n.2, p.360-370 abr./jun., 2012 http://www.rbspa.ufba.br ISSN 15199940

Tabela 2. Desdobramento da interação período de armazenamento X condimento para $\mathrm{pH}$, TBARS, umidade, força de cisalhamento e perdas por cocção de amostras de embutidos frescos preparados com carne de peito e pernas de poedeiras

\begin{tabular}{|c|c|c|c|c|}
\hline \multirow{3}{*}{ Condimento } & \multicolumn{4}{|c|}{ Período (dias) } \\
\hline & 0 & 3 & 6 & 9 \\
\hline & \multicolumn{4}{|c|}{$\mathrm{pH}$} \\
\hline Controle & $5,87^{\mathrm{A}}$ & $5,96^{\mathrm{A}}$ & $5,91^{\mathrm{A}}$ & $5,71^{\mathrm{aB}}$ \\
\hline Cravo & $5,87^{\mathrm{A}}$ & $5,94^{\mathrm{A}}$ & $5,92^{\mathrm{A}}$ & $5,59^{\mathrm{bB}}$ \\
\hline Orégano & $5,84^{\mathrm{A}}$ & $5,97^{\mathrm{A}}$ & $5,94^{\mathrm{A}}$ & $5,73^{\mathrm{aB}}$ \\
\hline \multirow[t]{2}{*}{ Alecrim } & $5,86^{\mathrm{A}}$ & $5,94^{\mathrm{A}}$ & $5,97^{\mathrm{A}}$ & $5,70^{\mathrm{aB}}$ \\
\hline & \multicolumn{4}{|c|}{ TBARS (mg de TMP/kg de amostra) } \\
\hline Controle & $0,27^{\mathrm{bB}}$ & $0,31^{\mathrm{bB}}$ & $0,28^{\mathrm{bcB}}$ & $0,40^{\mathrm{bA}}$ \\
\hline Cravo & $0,21^{\mathrm{bD}}$ & $0,45^{\mathrm{aB}}$ & $0,36^{\mathrm{aC}}$ & $0,52^{\mathrm{aA}}$ \\
\hline Orégano & $0,27^{\mathrm{b}}$ & $0,31^{\mathrm{b}}$ & $0,24^{\mathrm{b}}$ & $0,28^{\mathrm{c}}$ \\
\hline \multirow[t]{2}{*}{ Alecrim } & $0,34^{\mathrm{a}}$ & $0,34^{\mathrm{b}}$ & $0,32^{\mathrm{ac}}$ & $0,39^{\mathrm{b}}$ \\
\hline & \multicolumn{4}{|c|}{ Umidade (\%) } \\
\hline Controle & $63,55^{\mathrm{ab}}$ & $67,88^{\mathrm{a}}$ & 63,51 & 63,87 \\
\hline Cravo & $67,31^{\mathrm{aA}}$ & $62,50^{\mathrm{bB}}$ & $62,72^{\mathrm{B}}$ & $63,10^{\mathrm{B}}$ \\
\hline Orégano & $61,01^{\mathrm{b}}$ & $62,37^{\mathrm{b}}$ & 61,18 & 61,10 \\
\hline \multirow[t]{2}{*}{ Alecrim } & $63,16^{\mathrm{b}}$ & $64,22^{\mathrm{ab}}$ & 63,53 & 63,99 \\
\hline & \multicolumn{4}{|c|}{ Força de Cisalhamento $\left(\mathrm{kgf} / \mathrm{cm}^{2}\right)$} \\
\hline Controle & $4,556^{\mathrm{ab}}$ & 3,877 & 4,139 & 4,465 \\
\hline Cravo & $5,210^{\mathrm{aA}}$ & $4,856^{\mathrm{AB}}$ & $3,974^{\mathrm{B}}$ & $4,838^{\mathrm{AB}}$ \\
\hline Orégano & $4,445^{\mathrm{ab}}$ & 4,150 & 4,371 & 4,965 \\
\hline \multirow[t]{2}{*}{ Alecrim } & $3,818^{\mathrm{b}}$ & 3,860 & 4,188 & 4,740 \\
\hline & \multicolumn{4}{|c|}{ Perdas por cocção (\%) } \\
\hline Controle & $27,81^{\mathrm{AB}}$ & $31,41^{\mathrm{A}}$ & $16,53^{B}$ & $16,90^{B}$ \\
\hline Cravo & $23,40^{\mathrm{B}}$ & $35,57^{\mathrm{A}}$ & $16,04^{\mathrm{B}}$ & $24,60^{\mathrm{B}}$ \\
\hline Orégano & $22,08^{\mathrm{A}}$ & $25,04^{\mathrm{A}}$ & $18,29^{\mathrm{B}}$ & $26,36^{\mathrm{A}}$ \\
\hline Alecrim & 25,36 & 24,62 & 23,24 & 27,69 \\
\hline
\end{tabular}

Médias seguidas de letras maiúsculas (linhas) e minúsculas (colunas) diferentes diferem entre si pelo teste de Tukey a $5 \%$.

As amostras que não continham antioxidante natural (grupo controle) apresentaram aumento no número de TBARS aos nove dias de armazenamento. Esse fato corrobora os dados obtidos por Nunes et al. (2003), que armazenaram amostras de linguiça de frango tradicional durante oito dias e verificaram aumento no valor de malonaldeído (TBARS) durante a estocagem do produto.

As amostras que continham orégano e alecrim não apresentaram variação na oxidação quando armazenadas em diferentes períodos. No dia zero, a amostra que continha alecrim apresentou oxidação lipídica significativamente superior às amostras de controle, cravo e orégano, pois estas não diferiram entre si $(\mathrm{p}>0,05)$. Assim, no dia inicial das análises, houve diferença apenas para o tratamento que continha alecrim.

No terceiro dia, o valor de TBARS foi maior $(p<0,05)$ no tratamento que continha cravo, e os demais tratamentos apresentaram oxidação similar. No dias seis e nove, o tratamento que continha orégano foi o que apresentou menor 
oxidação em relação aos demais. Esse resultado concorda com as pesquisas de Du \& Ahn (2002), que também observaram efeito positivo do uso do orégano sobre a oxidação. Porém, no sexto dia de armazenamento o tratamento com orégano não diferiu do grupo controle $(p>0,05)$.

Ao avaliar o fator condimento dentro do período, nota-se que somente o tratamento que continha cravo apresentou variação de umidade com o passar do tempo. Ressalte-se que, no período zero de armazenamento, a umidade foi maior $(p<0,05)$ do que nos demais períodos, os quais não diferiram entre si. Tal resultado pode ser explicado devido à possível ação do cravo sobre a porcentagem de água livre e de água fracamente ligada da amostra, o que faz com que a técnica de obtenção de umidade em estufa $\left(105^{\circ} \mathrm{C}\right)$ não extraia completamente a água do produto. Resultados similares foram descritos por Silva (2004) com a adição de polifosfato em amostras de linguiça de carne de frango.

Ao analisar o efeito do período sobre a umidade dos tratamentos com condimentos, observam-se diferenças significativas entre os tipos de condimentos nos dias zero e três de armazenamento. No dia zero, o tratamento que continha cravo, como antioxidante natural, apresentou umidade maior $(\mathrm{p}<0,05)$ do que os tratamentos que continham alecrim e orégano, sem apresentar configurações díspares do grupo controle $(\mathrm{p}>0,05)$, porém. No terceiro dia de armazenamento, a maior umidade foi encontrada no grupo controle, que diferiu $(p<0,05)$ dos grupos que continham cravo e orégano, ao apresentar umidade similar à do grupo que continha alecrim.

No que diz respeito à força de cisalhamento, ao analisar o fator condimento dentro de cada período de armazenamento, observou-se que o uso de cravo proporcionou menor força de cisalhamento no sexto dia de armazenamento, quando comparado ao dia zero, sem apresentar desigualdades estatísticas dos demais períodos de armazenamento $(\mathrm{p}>0,05)$. As presenças de cravo e alecrim mostraram-se diferentes no dia zero de armazenamento, uma vez que as amostras que continham cravo apresentaram maior força de cisalhamento $(\mathrm{p}<0,05)$, sem mostrar diferenças em relação aos demais tratamentos.

Nas perdas por cocção, nota-se que, com exceção do tratamento que continha alecrim, todos sofreram variação para este parâmetro no decorrer do armazenamento. $\mathrm{O}$ grupo controle apresentou maior perda por cocção no terceiro dia de armazenamento, cujo valor não diferiu apenas do dia zero $(\mathrm{p}>0,05)$. O tratamento que possuía cravo também perdeu mais líquido, ao ser cozido no terceiro dia de armazenamento, o que o distanciou dos demais períodos $(\mathrm{p}<0,05)$. No sexto dia de armazenamento o tratamento que continha orégano teve significativa queda na perda por cocção, o que o diferiu dos demais períodos, os quais mostraram valores estatisticamente iguais entre si.

Observa-se interação entre período de armazenamento e condimento (antioxidante natural) para a cor das amostras na Tabela 3. Com os desdobramentos destas interações na Tabela 4.

No período inicial de armazenamento, o grupo controle teve luminosidade inferior à do grupo que continha cravo, não diferindo dos outros dois grupos. No terceiro e no nono dia, o tratamento controle mostrou a maior luminosidade, quando comparado aos demais, que não apresentavam dessemelhanças entre si $(\mathrm{p}>0,05)$. O grupo contendo cravo foi o que apresentou a menor luminosidade no sexto dia $(\mathrm{p}<0,05)$, diferindo dos demais, que apresentaram valores próximos. 
Rev. Bras. Saúde Prod. Anim., Salvador, v.13, n.2, p.360-370 abr./jun., 2012 http://www.rbspa.ufba.br ISSN 15199940

Tabela 3.Valores obtidos para cor (L, a e b) de amostras de embutidos frescos preparados com carne de poedeiras de descarte contendo diferentes antioxidantes naturais e armazenados por diferentes períodos

\begin{tabular}{lccc}
\hline \multicolumn{1}{c}{ Tratamentos } & $\mathrm{L}^{*}$ & $\mathrm{a}^{*}$ & $\mathrm{~b}^{*}$ \\
\hline Controle & & Condimento $(\mathrm{C})$ & 10,18 \\
Cravo & 48,10 & 10,60 & 9,46 \\
Orégano & 44,95 & 9,98 & 10,99 \\
Alecrim & 46,49 & 10,46 & 10,89 \\
\hline DMS & 47,04 & 9,40 & 0,75 \\
Teste F & 1,19 & 0,90 & $12,99^{* *}$ \\
\hline \multicolumn{4}{c}{} \\
\hline 0 & $17,80^{* *}$ & $5,23^{*}$ & 9,55 \\
3 & Armazenamento em dias $(\mathrm{A})$ & 9,40 \\
6 & 44,40 & 8,30 & 10,68 \\
9 & 46,94 & 10,50 & 11,89 \\
\hline DMS & 47,53 & 10,84 & 0,75 \\
Teste F & 47,73 & 10,78 & $34,63^{* *}$ \\
\hline F p/ Int. C X A & 1,19 & 0,90 & $14,45^{* *}$ \\
CV (\%) & $24,36^{* *}$ & $26,63^{* *}$ & 6,57 \\
\hline
\end{tabular}

$\mathrm{Na}$ mesma coluna, médias seguidas de letras diferentes indicam diferença significativa pelo teste de Tukey a $5 \%$. DMS $=$ Diferença Mínima Significativa. $*(\mathrm{P}<0,05) ; * *(\mathrm{P}<0,01), \mathrm{CV}=$ Coeficiente de variação.

Tabela 4. Desdobramento da interação período de armazenamento $X$ condimento para luminosidade (L), intensidade de vermelho(a) e amarelo (b) das amostras de embutidos frescos preparados com carne de peito e pernas de poedeiras

\begin{tabular}{lcccc}
\hline \multirow{2}{*}{ Tempero } & 0 & 3 & 6 & 9 \\
\cline { 2 - 4 } & \multicolumn{5}{c}{ Período (dias) } \\
\hline Controle & $42,00^{\mathrm{Bb}}$ & $50,19^{\mathrm{aA}}$ & $48,70^{\mathrm{aA}}$ & $51,52^{\mathrm{aA}}$ \\
Cravo & $46,94^{\mathrm{aA}}$ & $46,12^{\mathrm{bA}}$ & $41,78^{\mathrm{bB}}$ & $44,97^{\mathrm{bAB}}$ \\
Orégano & $44,74^{\mathrm{abB}}$ & $44,86^{\mathrm{bB}}$ & $49,08^{\mathrm{aA}}$ & $47,29^{\mathrm{bAB}}$ \\
Alecrim & $43,92^{\mathrm{abB}}$ & $46,57^{\mathrm{bB}}$ & $50,56^{\mathrm{aA}}$ & $47,13^{\mathrm{bB}}$ \\
\hline \multicolumn{5}{c}{ Intensidade de vermelho $(\mathrm{a})$} \\
\hline Controle & $8,83^{\mathrm{abB}}$ & $11,00^{\mathrm{abB}}$ & $13,78^{\mathrm{aA}}$ \\
Cravo & $9,65^{\mathrm{aB}}$ & $8,68^{\mathrm{bB}}$ & $8,62^{\mathrm{bB}}$ & $8,77^{\mathrm{bB}}$ \\
Orégano & $7,74^{\mathrm{abB}}$ & $10,93^{\mathrm{abA}}$ & $12,66^{\mathrm{aA}}$ & $12,97^{\mathrm{aA}}$ \\
Alecrim & $6,98^{\mathrm{bB}}$ & $11,41^{\mathrm{aA}}$ & $8,32^{\mathrm{bB}}$ & $10,48^{\mathrm{bA}}$ \\
\hline \multicolumn{5}{c}{ Intensidade de amarelo $(\mathrm{b})$} \\
\hline Controle & $7,88^{\mathrm{bB}}$ & $10,90^{\mathrm{aA}}$ & $10,62^{\mathrm{aA}}$ \\
Cravo & $10,58^{\mathrm{aAB}}$ & $6,65^{\mathrm{bC}}$ & $8,88^{\mathrm{bB}}$ & $11,31^{\mathrm{A}}$ \\
Orégano & $1,33^{\mathrm{aA}}$ & $9,20^{\mathrm{aB}}$ & $11,59^{\mathrm{aA}}$ & $11,74^{\mathrm{A}}$ \\
Alecrim & $8,40^{\mathrm{bB}}$ & $10,85^{\mathrm{aA}}$ & $11,62^{\mathrm{aA}}$ & $11,84^{\mathrm{A}}$ \\
\hline Mecrimy & & $12,68^{\mathrm{A}}$ \\
\hline
\end{tabular}

Médias seguidas de letras maiúsculas (linhas) e minúsculas (colunas) diferentes diferem entre si pelo teste de Tukey a $5 \%$ de significância. 
Os tratamentos controle e adicionado de cravo apresentaram valores significativamente maiores nos dias seis e nove de armazenamento, respectivamente para intensidade de vermelho. Já o grupo que continha orégano apresentou menores valores para o parâmetro no dia zero de armazenamento, o que o tornou diferente dos demais períodos, não distantes entre si. $\mathrm{O}$ tratamento que continha alecrim mostrou menores intensidades de vermelho nos dias zero e seis, e diferiu significativamente dos dias três e nove, que foram os períodos nos quais as amostras apresentaram maiores intensidades para esse parâmetro $(\mathrm{p}<0,05)$. No terceiro dia a situação foi inversa: o grupo alecrim foi superior ao grupo que continha cravo e apresentou maiores valores para intensidade de vermelho $(\mathrm{p}<0,05)$. No sexto dia, os tratamentos controle e com orégano foram os que apresentaram os maiores valores, e diferiu dos outros dois tratamentos (cravo e alecrim), que mostraram os menores valores $(\mathrm{p}<0,05)$. Ao armazenar as amostras por nove dias, verificou-se que as amostras de cravo apresentaram intensidade de vermelho maior do que as demais, com exceção das que continham alecrim, que por sua vez mostraram valor para intensidade de vermelho igual ao dos tratamentos controle e com orégano ( $>>0,05$ ).

$\mathrm{O}$ tratamento controle apresentou menor valor de b (amarelo) no dia zero de armazenamento $(\mathrm{p}<0,05)$, enquanto que nos demais períodos essa diferença não foi observada. Ao utilizar cravo, verificou-se que a intensidade de amarelo foi menor no terceiro dia e aumentou nos dias seis e nove, que diferiram entre si $(p<0,05)$. No terceiro dia de armazenamento, o tratamento adicionado de orégano mostrou intensidade de amarelo significativamente inferior aos demais, sem apresentar diferença significativa para essa característica entre os tempos zero, seis e nove. Com o alecrim a situação foi similar à do grupo com orégano, porém a intensidade de amarelo foi menor no dia zero, o que diferiu dos demais períodos, que apresentaram valores similares.

Ao comparar os tratamentos dentro de cada período, nota-se que no período zero os grupos controle e alecrim apresentaram os menores valores (Tabela 5), o que os distanciaram dos demais (cravo e orégano), que tiveram os maiores valores $(p<0,05)$. No terceiro dia, o tratamento com cravo teve a menor intensidade de amarelo, diferindo dos outros tratamentos, que apresentaram resultados iguais $(p>0,05)$. A mesma situação se repetiu no sexto dia, porém, nesse período de armazenamento, o tratamento com orégano não se distinguiu estatisticamente do grupo controle $(p>0,05)$. Não foram observadas diferenças $(\mathrm{p}<0,05)$ entre os tratamentos para intensidade de amarelo no nono dia de armazenamento. Houve efeito do fator condimento sobre todas as características sensoriais estudadas. Para a característica aceitação, a menor nota foi verificada no tratamento que continha cravo, porém esse não diferiu do que continha alecrim $(p>0,05) . \quad O$ orégano proporcionou maiores notas em relação ao parâmetro textura, distinguindo-se dos demais tratamentos, que eram iguais entre si ( $p>0,05)$. Tal resultado está relacionado à menor perda por cocção observada neste tratamento, que proporcionou maior suculência e maciez as amostras (SILVA, 2004).

O tratamento com cravo foi o que recebeu as menores notas quanto ao sabor, sem diferir do tratamento com alecrim, que por sua vez, não se distanciou dos demais ( $>>0,05)$. Em relação à preferência, novamente $\mathrm{o}$ tratamento que continha cravo obteve notas inferiores, diferindo do grupo controle $(\mathrm{p}<0,05)$ que mostrou-se o de menor preferência pelos provadores. Tais 
Rev. Bras. Saúde Prod. Anim., Salvador, v.13, n.2, p.360-370 abr./jun., 2012 http://www.rbspa.ufba.br ISSN 15199940

resultados discordam dos de Scheid et al. (2003), que relataram boa aceitação por provadores de linguiças temperadas com o cravo-da-índia. O fator período de armazenamento não mostrou influência sobre as características sensoriais das amostras.

Tabela 5. Valores obtidos na análise sensorial de amostras de embutidos frescos preparados com carne de peito e pernas de poedeiras de descarte contendo diferentes antioxidantes naturais e armazenados por diferentes períodos

\begin{tabular}{|c|c|c|c|c|}
\hline Tratamentos & Aceitação & Textura & Sabor & Preferência \\
\hline \multicolumn{5}{|c|}{ Condimento $(\mathrm{C})$} \\
\hline Controle & $6,96^{\mathrm{a}}$ & $6,90^{\mathrm{b}}$ & $7,20^{\mathrm{a}}$ & $6,95^{\mathrm{a}}$ \\
\hline Cravo & $6,08^{\mathrm{b}}$ & $6,10^{\mathrm{b}}$ & $5,92^{\mathrm{b}}$ & $5,96^{\mathrm{b}}$ \\
\hline Orégano & $6,76^{\mathrm{a}}$ & $8,01^{\mathrm{a}}$ & $6,95^{\mathrm{a}}$ & $6,65^{\mathrm{ab}}$ \\
\hline Alecrim & $6,37^{\mathrm{ab}}$ & $6,34^{\mathrm{b}}$ & $6,56^{\mathrm{ab}}$ & $6,26^{\mathrm{ab}}$ \\
\hline DMS & 0,68 & 0,92 & 0,70 & 0,69 \\
\hline Teste F & $4,52^{*}$ & $3,70^{*}$ & $8,44 * *$ & $5,25^{*}$ \\
\hline \multicolumn{5}{|c|}{ Armazenamento em dias (A) } \\
\hline 0 & 6,50 & 6,56 & 6,76 & 6,53 \\
\hline 3 & 6,35 & 6,18 & 6,37 & 6,10 \\
\hline 6 & 6,67 & 6,93 & 6,79 & 6,56 \\
\hline 9 & 6,65 & 6,68 & 6,70 & 6,64 \\
\hline DMS & 0,68 & 0,92 & 0,70 & 0,69 \\
\hline Teste F & $0,62^{\mathrm{NS}}$ & $1,36^{\mathrm{NS}}$ & $1,02^{\mathrm{NS}}$ & $1,60^{\mathrm{NS}}$ \\
\hline F p/ Int. C X A & $0,25^{\mathrm{NS}}$ & $0,89^{\mathrm{NS}}$ & $0,51^{\mathrm{NS}}$ & $0,47^{\mathrm{NS}}$ \\
\hline $\mathrm{CV}(\%)$ & 22,86 & 36,11 & 23,08 & 23,37 \\
\hline
\end{tabular}

Na mesma coluna, médias seguidas de letras diferentes indicam diferença significativa pelo teste de Tukey a $5 \%$ de probabilidade. DMS = Diferença Mínima Significativa. * $(\mathrm{P}<0,05) ; * *(\mathrm{P}<0,01)$, $\mathrm{CV}=$ Coeficiente de variação. NS=Não significativo.

Assim, a partir dos dados apresentados, conclui-se que a utilização de orégano na formulação do embutido de carne de frango retardou a oxidação do produto e mostrou a melhor preferência na análise sensorial. Por outro lado o cravo-daíndia apresentou menor eficiência na estabilidade oxidativa das mostras e menor aceitação sensorial.

\section{REFERÊNCIAS}

ANTUNES, P.; RÉU, C.; SOUSA, J.C.; PEIXE, L.;PESTANA, N. Incidence of Salmonella from poultry products and their susceptibility to antimicrobial agents. International Journal of Food Microbiology, v.82, n.2, p.97-103, 2003. 
Rev. Bras. Saúde Prod. Anim., Salvador, v.13, n.2, p.360-370 abr./jun., 2012 http://www.rbspa.ufba.br ISSN 15199940

ASSOCIATION OF OFFICIAL ANALYTICAL CHEMISTS - AOAC. Official methods of analysis of Association of Official Analytical Chemists. Methods: 934.01, 923.03, 945.38,942.15,973.41. 17th ed.

Gaithersburg, 2000.

CORTE, O.O.; FELÍCIO, P.E.; CIA, G. Sistematização da avaliação final de bovinos e bubalinos. III. Qualidade da carne. Boletim Técnico do Centro de Tecnologia de Carnes, n.3, p.66-76, 1979.

DU, M.; AHN, D.U. Effect of antioxidants on the quality of irradiated sausages prepared with turkey thigh meat. Poulty Science,v.81,p.1251-1256, 2002.

GARCIA, C.E.R.; YOUSSEF, E.Y.; OLIVO, R.; SHIMOKOMAKI, M. Antioxidantes utilizados na indústria cárnea. Quais são os aditivos inibidores da rancidez nos produtos cárneos?

Revista Nacional da Carne, v.26, n.299, p.36-51, 2002.

KOMIYAMA, C.M.; MENDES, A.A.; SANFELICE, C.; CAÑIZARES, M.C.; ROÇA, R.O.; TAKAHASHI, S.E.; RODRIGUES, L.; CAÑIZARES, G.I.L; PAZ, I.C.L.A.; CARDOSO, K.F.G. Qualidade físico-química e sensorial da carne de peito de matrizes pesadas de descarte. Ciência Rural, v.40, n.7, p.1623-1629, 2010.

MARIUTTI, L.R.B.; ORLIEN, V.; BRAGAGNOLO, N.; SKIBSTED, L.H. Effect of sage and garlic on lipid oxidation in high-pressure processed chicken meat. European Food Research and Technology, n.227, n.2, p.337-344, 2008.
MEILGAARD, M.; CIVILLE, G.V.; CARR, B.T. Sensory evaluation techniques. Boca Raton: CRC Press, 1991. 281p.

MENDES, A.A. Regionalização da avicultura. Informativo Técnico Biovet, n.25, 2005. Disponível em: < http://www.biovet.com.br/downloads/inf o-tecnico/25.pdf>. Acesso em: $12 \mathrm{fev}$. 2011.

NASSU, R.T.; GONÇALVES, L.A.G.; BESERRA, F.J. Efeito do teor de gordura nas características químicas e sensoriais de embutido fermentado de carne de caprinos. Pesquisa Agropecuária Brasileira, v.37, n.8, p.1169-1173, 2002.

NUNES, M.L.; FIGUEIREDO, M.J.; MADRUDA, M.S.; LIMA, F.M.S.; BISCONTINI, T.M. Efeito de antioxidantes e das condições de estocagem na oxidação lipídica de lingüiças de frango. Revista nacional da carne, n.319, p.36-48, 2003.

PIKUL , J.; LESZCZYNSKI, D. E.; KUMMEROW, F. A. Evaluation of tree modified TBA methods for measuring lipid oxidation in chicken meat. Journal of Agricultural and Food and Chemistry,v. 37,p.1309-1313, 1989.

SAS INSTITUTE. SAS user's guide: statistics. Release 8.02. Cary, 1999.

SCHEID, G.A.; MINIM, V.P.R.; GOMIDE, L.A.; VANETTI, M.C.D.; MINIM, L.A.; COIMBRA, J. S,R. Avaliação físico-química e sensorial de salame tipo italiano contendo diferentes concentrações de cravo-da-índia (Eugenia caryophyllus). Ciências Agrotecnologia, Edição Especial, p.1576-1583, 2003. 
Rev. Bras. Saúde Prod. Anim., Salvador, v.13, n.2, p.360-370 abr./jun., 2012 http://www.rbspa.ufba.br ISSN 15199940

SILVA, L.P.A. Avaliação do prazo de vida comercial de lingüiça de frango preparada com diferentes concentrações de polifosfato. 2004. 74p. Dissertação (Mestrado em Medicina Veterinária) - Universidade Federal Fluminense, Niterói.
SOUZA, H.B.A.; SCATOLINI, A.M.; BOIAGO, M.M.; LEONEL, F.R.;

SOUZA, P.A. Utilização de amaciante em carne de matrizes de descartes. In: CONFERÊNCIA APINCO DE CIÊNCIA E TECNOLOGIA AVÍCOLAS, 2006, Santos. Anais... Santos: Fundação Apinco de Ciência e Tecnologia Avícolas, 2006. p.153.

Data de recebimento: 17/05/2011

Data de aprovação: 19/04/2012 